\title{
KOMUNITAS SERANGGA HAMA PADA KOMODITI JAGUNG DI KECAMATAN MOOTILANGO, KABUPATEN GORONTALO PROVINSI GORONTALO
}

\section{PEST INSECT COMMUNITIES ON CORN COMMODITIES IN THE DISTRICT OF MOOTILANGO, GORONTALO REGENCY, GORONTALO PROVINCE}

\author{
Muskina Dj. Rahman'), M. F. Dien') dan J. E. Mamahit') \\ 1)Balai Proteksi Tanaman Pangan dan Hortikultura Provinsi Gorontalo \\ 2)Perhimpunan Entomologi Indonesia Cabang Manado, Sulawesi Utara \\ 3)Fakultas Pertanian, Universitas Sam Ratulangi
}

\begin{abstract}
The research was aimed to determine the types of insect pests that attack corn in storage. This was conducted from April to July, 2011 in the district of Mootilango, Gorontalo Province. The sampling was conducted in a purposive sampling, which is taking the samples of suspected commodity corn pests. Samples were taken by the corn at the corner and the center of the diagonal area of which as many as 250 grams, then put them into a jar and covered with a soft cloth. Sampling was carried out four times in every two weeks. The research found seven types of insect pests on the corn in storage, which consisted of six orders of Coleoptera and 1 order of Lepidoptera. The results showed that, the identification of insect pests were: Sitophilus sp., Ahasverus sp., Oryzaephilus sp., Tribolium sp., Rhyzopertha sp., Cryptolestes sp., and Sitotroga sp. Sitophilus sp., an insect pest with the highest population, was reached an average of 79.01 individuals, followed by Tribolium sp. (14.79 individuals), Cryptolestes sp. (13.30 individuals), Oryzaephilus sp. (11.26 individuals), Ahasverus sp. (7.45 individuals), Sitotroga sp. (4.30 individuals) and Rhyzopertha sp. (2.15 individuals).
\end{abstract}

Keywords : Insect pest storage, corn

\begin{abstract}
ABSTRAK
Penelitian ini bertujuan untuk mengetahui jenis-jenis serangga hama yang menyerang jagung pipilan di penyimpanan. Penelitian telah dilakukan sejak bulan April sampai dengan Juli 2011 di Kecamatan Mootilango, Kabupaten Gorontalo, Provinsi Gorontalo. Pengambilan sampel dilakukan secara purposive sampling yaitu dengan mengambil sampel komoditi jagung pipilan yang diduga terserang hama. Sampel komoditi jagung pipilan diambil pada bagian sudut dan bagian tengah (diagonal) yang masingmasing sebanyak 250 gram, kemudian dimasukkan ke dalam stoples dan disungkup dengan kain kasa halus. Pengambilan sampel dilakukan sebanyak 4 kali dengan interval waktu 2 minggu sekali. Hasil penelitian ditemukan 7 jenis serangga hama pada jagung pipilan dipenyimpanan yang terdiri dari 6 ordo Coleoptera dan 1 ordo Lepidoptera. Hasil identifikasi menunjukkan bahwa serangga hama yang ditemukan adalah Sitophilus sp., Ahasverus sp., Oryzaephilus sp., Tribolium sp., Rhyzopertha sp., Cryptolestes, dan Sitotroga sp. Sitophilus sp. merupakan serangga hama dengan populasi tertinggi yakni mencapai rata-rata 79,01 individu, kemudian diikuti oleh Tribolium sp. (14,79 individu), Cryptolestes sp. (13,30 individu), Oryzaephilus sp. (11,26 individu), Ahasverus sp. (7,45 individu), Sitotroga sp. (4,30 individu) dan Rhyzopertha sp. (2,15 individu)

Kata kunci : serangga hama gudang, jagung pipilan
\end{abstract}

Eugenia Volume 18 No. 3 Desember 2012 


\section{PENDAHULUAN}

Jagung sebagai bahan pangan, dapat dikonsumsi langsung maupun perlu pengolahan seperti jagung rebus, bakar, maupun dimasak menjadi nasi. Sebagai bahan pakan ternak, biji pipilan kering digunakan untuk pakan ternak bukan ruminan seperti ayam, itik, puyuh, dan babi, sedangkan seluruh bagian tanaman (brangkasan) jagung atau limbah jagung, baik yang berupa tanaman jagung muda maupun jeraminya di-manfaatkan untuk pakan ternak ruminansia. Selain itu, jagung juga berpotensi sebagai bahan baku industri makanan, kimia farmasi dan industri lainnya yang mempunyai nilai tinggi, seperti tepung jagung, gritz jagung, minyak jagung, dextrin, gula, etanol, asam organik, dan bahan kimia lain. Disamping itu, bahan tanaman jagung yang umum disebut benih, merupakan bagian terpenting dalam suatu proses produksi jagung itu sendiri (Anonim, 2010).

Provinsi Gorontalo adalah salah satu penghasil jagung di Indonesia dan telah di ekspor ke beberapa Negara di Asia. Jumlah ekspor jagung dari Provinsi Gorontalo ke sejumlah negara seperti Korea, China dan Malaysia, telah mencapai 20 ribu ton hingga Maret 2010. Berdasarkan data Dinas Pertanian, terjadi peningkatan signifikan pada jumlah ekspor jagung yakni tahun 2005 sebanyak 90 ribu ton dan tahun 2010 sebanyak 177 ribu ton dan jagung telah dipilih menjadi komoditi unggulan daerah tersebut (Anonim, 2010a).

Penyimpanan jagung oleh petani, pedagang, dan produsen benih dilakukan untuk berbagai kepentingan, antara lain untuk keamanan pangan, kebutuhan benih pada musim berikutnya, dipasok ke tempat lain atau menunggu harga yang lebih baik. Selama penyimpanan, biji jagung dapat terserang oleh berbagai spesies serangga hama gudang dan tikus (Sidik dan Halid, 1983).

Hama gudang merupakan hama yang

selalu menyebabkan kerusakan baik secara kuantitatif maupun kualitatif pada bahan simpanan. Kerusakan kuantitatif mengarah pada berkurangnya jumlah, sedangkan kerusakan kualitatif mengarah pada turunnya mutu bahan simpanan yang diserangnya. Hama gudang dapat dijumpai sejak prapanen, dalam proses pengangkutan sampai pada tempat penyimpanan di dalam gudang. Dari berbagai tempat yang dapat dihuni oleh serangga, gudang tempat penyimpanan merupakan tempat berkembang biak yang sangat ideal bagi hama. Hal ini dikarenakan di dalam gudang tersedia makanan yang melimpah, kondisi lingkungan yang kondusif untuk berkembang biak, serta keadaan musuh alami yang cukup rendah. Oleh sebab itu, induksi beberapa serangga saja dalam gudang penyimpanan dapat berkembang dengan sangat cepat dan menimbulkan kerusakan yang sangat besar dalam waktu yang relatif singkat (Anonim, 2008; Sidik dan Halid, 1983; Fitria dkk., 2009).

Komoditi jagung oleh masyarakat tadi di Kecamatan Mootilango pada umumnya disimpan dalam bentuk pipilan yang sudah kering. Jagung pipilan dimasukkan ke dalam karung dan siap untuk dijual (Anonim, 2010a).

Serangga hama penting yang menyerang komoditi jagung di Indonesia adalah Sitophilus zeamais (Curculionidae, Coleoptera), Tribolium castaneum (Tenebrionidae, Coleoptera), Rhizopertha dominica (Bostrychidae, Coleoptera), Cryptolestes ferrugineus (Cucujidae, Coleoptera), Tenebroides mauritanicus (Trogosstidae, Coleoptera), (Fitria dkk., 2009; Harahap, 2003; Kalshoven, 1981; Kartasapoetra, 1991; Mangoendihardjo, 1978; Ridwan, 2009; Saenong dan Hipi, 2005; Sembel dkk., 1992; Tandiabang $d k k ., 2009)$.

Penelitian ini bertujuan untuk mengetahui jenis-jenis serangga hama yang menyerang komoditi jagung pada penyimpanan di Kecamatan Mootilango.

\section{METODE PENELITIAN}

Penelitian dilaksanakan di Kecamatan Mootilango Kabupaten Gorontalo, Provinsi Gorontalo, sejak bulan April sampai dengan Juli 2011. Metode penelitian yakni secara survey pada lokasi-lokasi penampungan/penyimpanan jagung pipilan yang tersebar di Desa Huyula, Desa Helumo, Desa Talumopatu, dan Desa Pilomonu, Kecamatan Mootilango.

Pengambilan sampel dilakukan secara purposive sampling yaitu dengan mengambil sampel komoditi jagung pipilan yang diduga terserang hama. Kriteria sampel terserang hama 
ditandai dengan terdapatnya serangga baik telur, larva, pupa, nimfa dan imago pada sampel dan ataupun adanya gejala serangan pada sampel

Sampel komoditi jagung pipilan diambil pada bagian sudut dan bagian tengah (diagonal) yang masing-masing sebanyak 250 gram, kemudian dimasukkan ke dalam stoples dan disungkup dengan kain kasa halus. Pengambilan sampel dilakukan sebanyak 4 kali dengan interval waktu 2 minggu sekali. Masing-masing sampel diberi label sesuai tempat pengambilannya, kemudian di bawa ke laboratorium untuk di amati.

\section{Pengamatan Jenis Hama}

Serangga hama yang ditemukan disortir/ dipisahkan menurut jenis dan lokasi pengambilan-

$$
\text { Rata-rata populasi hama }=\frac{\text { Jumlah individu hama yang ditemukan }}{\text { Jumlah pengamatan }}
$$

\section{HASIL DAN PEMBAHASAN}

\section{Jenis Hama}

Hasil penelitian menunjukkan bahwa ditemukan 7 jenis serangga hama pada komoditi jagung dipenyimpanan yang terdiri dari 6 ordo Coleoptera dan 1 ordo Lepidoptera. Dari hasil identifikasi menggunakan pustaka Buntin et. al. (2003); Brower, J. 2003; Ebeling, W. (2002); Zimmerman (1987) dan Halstead, D. G. H, (1986), bahwa serangga-serangga hama tersebut adalah :

\section{Sitophilus sp.}

Serangga ini diklasifikasikan ke dalam phylum Arthropoda, Sub-phyllum Mandibulata, Kelas Insecta, Sub-klas Pterygota, Ordo Coleoptera, Famili Curculionidae, Genus Sitophilus. Imago berwarna coklat kemerahan dan memiliki bintik-bintik coklat kemerahan yang membentuk corak pada elytra. Tubuh imago berbentuk lonjong dan berukuran panjang $4-4,5 \mathrm{~mm}$ dan lebar 1,1-1,3 mm. Memiliki moncong dan terdapat antenna yang berbentuk Lamellate (Gambar 1). Hama ini ditemukan pada setiap lokasi sampel dengan rata-rata populasi 79,01 individu.

\section{Ahasverus sp.}

Serangga ini diklasifikasikan ke dalam phylum Arthropoda, Sub-phyllum Mandibulata, nya. Sampel hama dikoleksi di dalam alkohol $70 \%$ untuk diidentifikasi. Identifikasi serangga hama dilakukan di Laboratorium Hama dan Penyakit Tumbuhan, Fakultas Pertanian, Universitas Sam Ratulangi, Manado menggunakan bahan pustaka Buntin et al. (2003); Brower, J. 2003; Ebeling, W. (2002); Zimmerman (1987) dan Halstead, D. G. H, (1986).

\section{Pengamatan Populasi Hama}

Serangga yang ditemukan disortir/pisahkan kemudian dihitung jumlahnya. Untuk menghitung rata-rata populasi hama digunakan formula sebagai berikut :

Kelas Insecta, Sub-klas Pterygota, Ordo Coleoptera, Famili Cucujidae, Genus Ahasverus. Imago berwarna coklat kemerah-merahan dan berukuran panjang kira-kira $2-3 \mathrm{~mm}$. Kedua tepi anterior dari protoraks terdapat tonjolan seperti gigi. Antena terdiri dari 11 ruas dengan bentuk gada dan memiliki tarsi 5 ruas (Gambar 2). Hama ini ditemukan pada setiap lokasi sampel dengan ratarata populasi 7,45 individu.

\section{Oryzaephilus sp.}

Serangga ini diklasifikasikan ke dalam phylum Arthropoda, Sub-phyllum Mandibulata, Kelas Insecta, Sub-klas Pterygota, Ordo Coleoptera, Famili Silvanidae, Genus Oryzaephilus. Imago berwarna coklat tua kemerahan berukuran panjang kira-kira 1-2 mm dan lebar 0,5$0,6 \mathrm{~mm}$. Tubuh agak langsing dan pipih, terdapat gerigi sebanyak 6 pasang pada masing-masing samping prothoraks. Kepala berbentuk menyerupai segitiga, terdapat garis membujur pada elytra dan prothoraxnya. Antenna yang berbentuk Clavate (Gambar 3). Hama ini ditemukan di setiap lokasi sampel dengan populasi rata-rata 11,26 Individu.

\section{Tribolium sp}

Serangga ini diklasifikasikan ke dalam phylum Arthropoda, Sub-phyllum Mandibulata, Ke- 
las Insecta, Sub-klas Pterygota, Ordo Coleoptera, Famili Tenebrionidae, Genus Tribolium.

Imago berwarna coklat kehitaman berukuran panjang kira-kira $7-7,5 \mathrm{~mm}$ dan lebar 2 . Antena berbentuk clavate menyerupai gada, ruasruas membesar secara teratus dari arah pangkal ke ujung (Gambar 4). Hama ini ditemukan pada setiap lokasi sampel dengan rata-rata populasi sebesar 14,79 individu.

\section{Rhyzopertha sp}

Serangga ini diklasifikasikan ke dalam phylum Arthropoda, Sub-phyllum Mandibulata, Kelas Insecta, Sub-klas Pterygota, Ordo Coleoptera, Famili Bostrichidae, Genus Rhyzopertha.

Imago berwarna berwarna coklat tua hingga hitam. Tubuh berbentuk seperti sulinder dan berukuran panjang kira-kira $3 \mathrm{~mm}$ dan lebar $1 \mathrm{~mm}$, permukaan thorax dan sayap depan (elytra) agak kasar dan mempunyai bintik-bintik kecil; sedangkan pada pronotum terdapat tonjolan-tonjolan kecil. Pronotum terlihat menyerupai helm yang menutupi kepalanya (Gambar 5). Hama ini ditemukan pada setiap lokasi sampel dengan rata-rata populasi 2,15 individu.

\section{Cryptolestes sp.}

Serangga ini diklasifikasikan ke dalam phylum Arthropoda, Sub-phyllum Mandibulata, Kelas Insecta, Sub-klas Pterygota, Ordo Coleoptera, Famili Cucujidae, Genus Cryptolestes. Imago berbentuk pipih berwarna coklat kemarahan dengan ukuran tubuh panjang kira-kira $2,5 \mathrm{~mm}$ dan lebar $0,5 \mathrm{~mm}$. Kepala berukuran hampir sama besar dengan thorax. Memiliki antenna yang berbentuk serrate. Tarsi pada masing-masing tungkai berjumlah 4 ruas (Gambar 6). Hama ini ditemukan pada penampungan jagung di semua lokasi sampel dengan rata-rata populasi sebesar 13,30 individu.

\section{Sitotroga sp.}

Serangga ini diklasifikasikan ke dalam phylum Arthropoda, Sub-phyllum Mandibulata, Kelas Insecta, Sub-klas Pterygota, Ordo Lepidoptera, Famili Gelechiidae, Genus Sitotroga.
Imago berwarna kuning kecoklatan dan berukuran kira-kira 3-4 mm dengan rentang sayap kira-kira $15 \mathrm{~mm}$ (Gambar 7). Hama ini ditemukan pada semua lokasi sampel dengan rata-rata populasi 4,3 individu.

Pengamatan terhadap populasi serangga hama ternyata Sitophilus sp. merupakan serangga hama yang memiliki populasi tertinggi yakni mencapai rata-rata 79,01 individu, kemudian diikuti oleh Tribolium sp. (14,79 individu), Cryptolestes sp. (13,30 individu), Oryzaephilus sp. (11,26 individu), Ahasverus sp. (7,45 individu), Sitotroga sp. (4,30 individu) dan Rhyzopertha sp. (2,15 individu), seperti terlihat pada Tabel 1.

Melihat Tabel 1, ternyata jenis serangga dengan populasi tertinggi yang ditemukan pada sampel jagung adalah Sitophilus sp. $(79,01$ individu). Hal ini menunjukkan bahwa Sitophilus sp. merupakan hama utama pada komoditi jagung.

Mejia (1991) menyatakan bahwa Sitophilus zeamais Motsch merupakan salah satu hama penting yang dominan menyerang biji jagung dan sorgum pada periode penyimpanan. Hama ini menyerang dengan merusak biji, menggerek dan melubangi biji dan meninggalkan sisa-sisa gerekan berupa bubuk.

Imago betina dapat mencapai umur 3-5 bulan dan dapat menghasilkan telur sampai 300 400 butir, oleh karena itu perkembangan hama ini sangat cepat. Siklus hidup hama ini sekitar 28-90 hari, tetapi umumnya selama \pm 31 hari. Panjang pendeknya siklus hidup hama ini tergantung pada temperatur ruang simpan, kelembaban di ruang simpan, dan jenis produk yang diserang (Mangoendihardjo, 1978). Selanjutnya Melchor (1981), menyatakan bahwa perkembangan Sitophilus zeamais Motsch sangat dipengaruhi oleh varietas jagung.

Parker (2009) Sitophilus oryzae bersifat kosmopolit atau tersebar luas di berbagai tempat di dunia. Kerusakan yang ditimbulkan oleh hama ini termasuk berat, bahkan sering dianggap sebagai hama paling merugikan produk pepadian. Rendahnya populasi serangga hama lainnya diduga disebabkan karena musuh alami. Selain jenis serangga hama, ternyata ditemukan pula beberapa serangga lainnya yang diduga sebagai parasitoid. Keempat jenis parasitoid yang ditemukan belum diidentifikasi. 


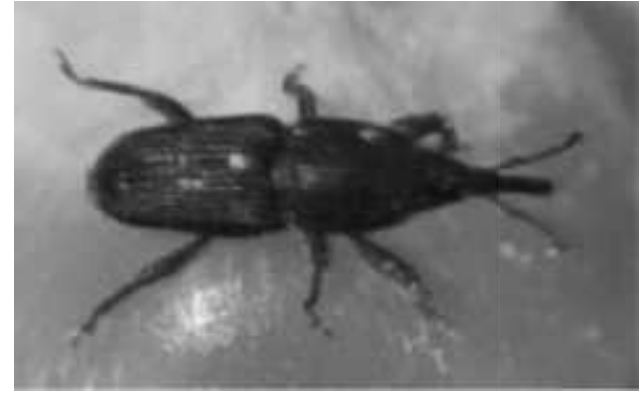

Gambar 1. Sitophilus sp.

(Figure 1. Sitophilus sp.)

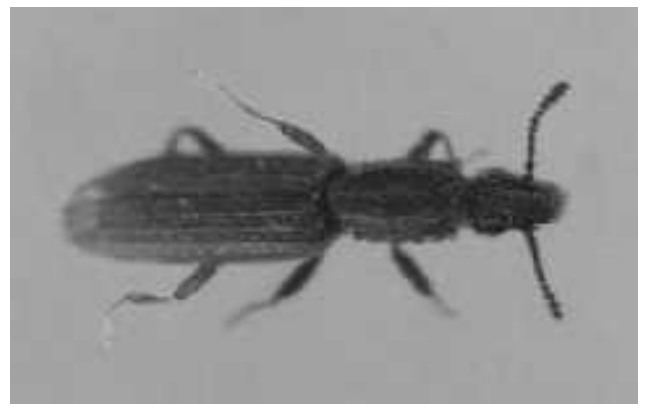

Gambar 3. Oryzaephilus sp.

(Figure 3. Oryzaephilus sp.)

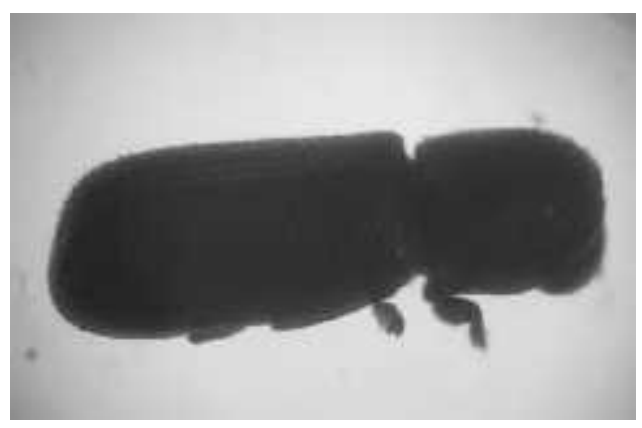

Gambar 5. Rhyzopertha sp.

(Figure 5. Rhyzopertha sp.)

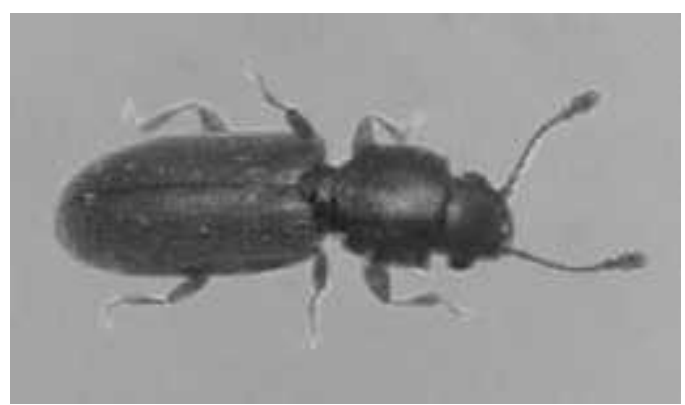

Gambar 2. Ahasverus sp.

(Figure 2. Ahasverus sp.)

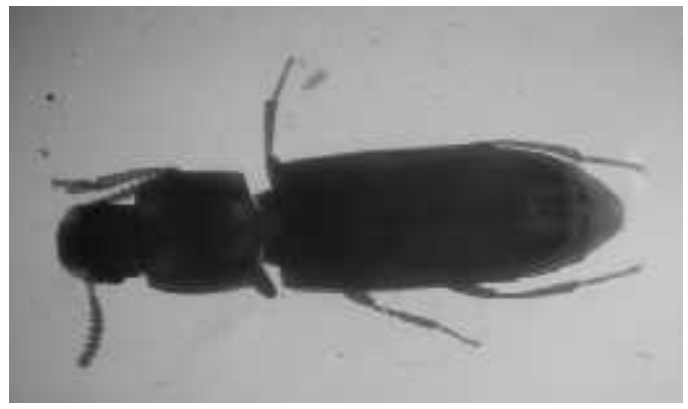

Gambar 4. Tribolium sp.

(Figure 4. Tribolium sp.)

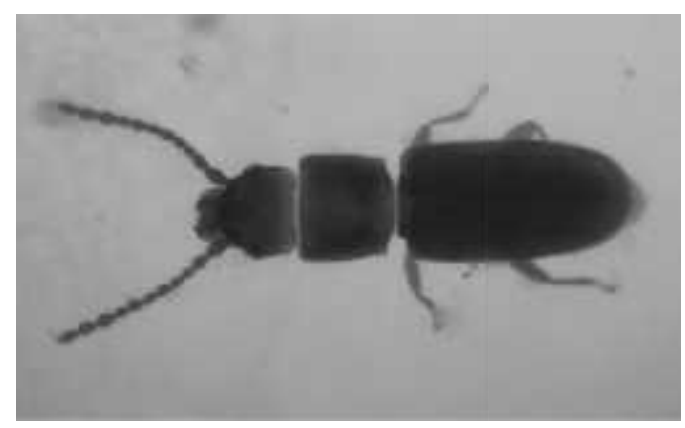

Gambar 6. Cryptolestes sp.

(Figure 6. Cryptolestes sp.)

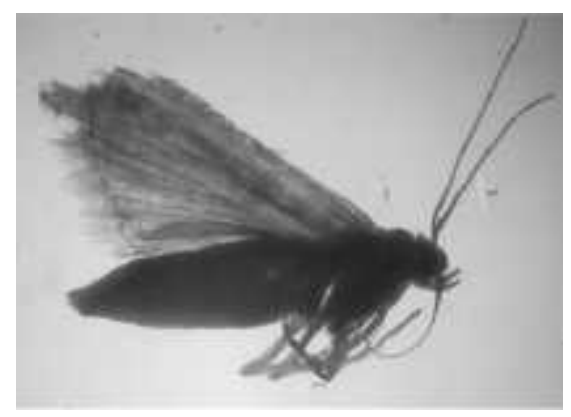

Gambar 7. Sitotroga sp.

(Figure 7. Sitotroga sp.). 
Tabel 1. Rata-rata Populasi Hama pada Komoditi Jagung di Kecamatan Mootilango, Kabupaten Gorontalo

(Table 1. The Average Population of Pests on the Corn commodities Corn in District Mootilango, Gorontalo Province)

\begin{tabular}{|c|c|c|c|c|c|}
\hline \multirow{2}{*}{ Jenis hama } & \multicolumn{4}{|c|}{ Lokasi sampel (desa) } & \multirow{2}{*}{ Rata-rata } \\
\hline & Huyula & Helumo & Talumopatu & Pilomonu & \\
\hline Sitophilus sp. & 75,62 & 74,62 & 93,87 & 71,93 & 79,01 \\
\hline Tribolium sp. & 14,93 & 16,25 & 16,25 & 11,75 & 14,79 \\
\hline Cryptolestes sp. & 11,93 & 15,12 & 12,43 & 13,75 & 13,30 \\
\hline Oryzaephilus sp. & 8,56 & 9,37 & 13,37 & 13,75 & 11,26 \\
\hline Ahasverus sp. & 10,93 & 9,25 & 3,0 & 6,62 & 7,45 \\
\hline Sitotroga sp. & 4,43 & 4,37 & 4,62 & 3,81 & 4,30 \\
\hline Rhyzopertha sp. & 2,0 & 2,25 & 2,5 & 1,86 & 2,15 \\
\hline Rata-rata & 18,34 & 18,74 & 20,82 & 17,63 & 18,88 \\
\hline
\end{tabular}
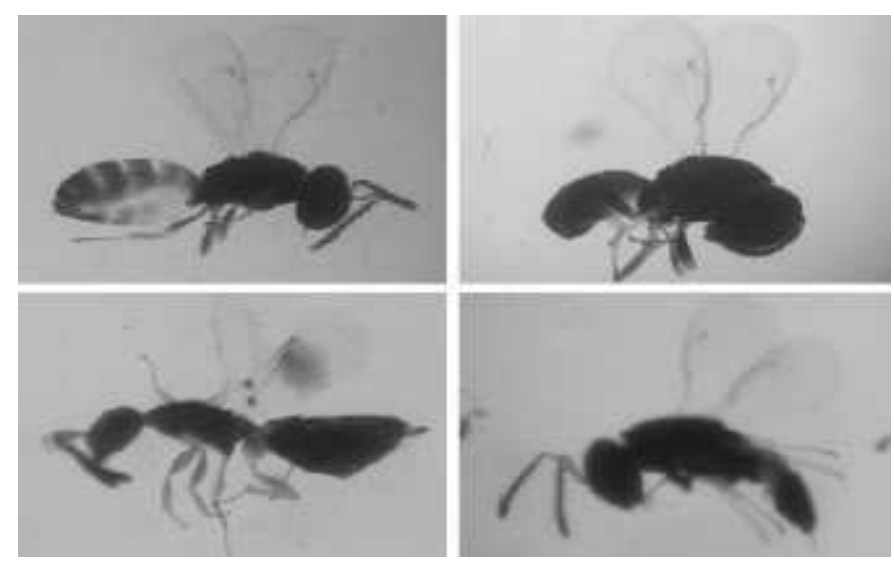

Gambar 8. Beberapa Parasitoid yang Ditemukan

(Figure 8. Some Parasitoids Are Found)

Parasitoid dapat diartikan sebagai serangga yang sebagian aktifitas hidupnya (telur, larva dan pupa) dilakukan pada (di dalam atau di luar) tubuh inangnya. Umumnya parasitoid memiliki ukuran tubuh yang lebih kecil atau sama besar dengan inangnya. Dalam perkembangannya parasitoid hanya membutuhkan satu individu inang, oleh karena itu dikenal parasitoid telur, yaitu parasitoid yang menyerang dan hidup pada stadia telur inang. Sifat dan perilaku parasitoid bervariasi menurut jenisnya. Beberapa spesies memiliki daya mencari dan menemukan inangnya yang lebih baik dari spesies lainnya, memiliki daya adaptasi terhadap lingkungan yang selalu berubah-ubah, memiliki daya kompetisi, dan memiliki daya reproduksi yang tinggi (Huffaker and Messenger, 1976).
Parasitoid merupakan salah satu komponen musuh alami yang berperan penting dalam mengontrol populasi hama di alam. Untuk efektifitas suatu parasitoid dalam suatu pengendalian maka perlu diketahui sifat-sifat biologinya, mekanisme parasitasi dan jenis-jenis parasitoid penting. Beberapa jenis parasitoid yang diketahui menyerang serangga hama gudang diantaranya Anisopteromalus sp., Habrobracon sp., dan Bracon hebetor (Brower, 2003, Ghimire and Thomas, 2002).

\section{KESIMPULAN DAN SARAN}

\section{Kesimpulan}

Terdapat 7 jenis serangga hama pada komoditi jagung di Kabupaten Gorontalo yaitu 
Sitophilus sp.. Ahasverus sp., Oryzaephilus sp., Tribolium sp., Rhyzopertha sp., Cryptolestes sp., dan Sitotroga sp.

Sitophilus sp. memiliki rata-rata populasi tertinggi yakni mencapai 79,01 individu dan terendah Rhyzopertha sp. 2,15 individu.

\section{Saran}

Perlu dilakukan penelitian untuk mengetahui penyebaran, jenis dan padat populasi serangga hama pada komoditi jagung pipilan di Provinsi Gorontalo.

Perlu dilakukan penelitian untuk mengetahui jenis dan potensi parasitoid pada berbagai jenis serangga hama gudang.

\section{DAFTAR PUSTAKA}

Anonim. 2008. Most Important Pest on Werehouse (Post-Harvest Pes). http://www pestwerehouse.blogspot.com/. (Diakses pada tgl 9 Maret 2011).

2010. Karakteristik Komoditas Jagung dalam Usaha Budidaya Jagung. http://binaukm.com/2010/06/karakteristik. komoditas.jagung.dalam.usaha.budidaya. jagung/. (Diakses pada tgl 12 Maret 2011).

2010a. Ekspor Jagung Gorontalo Capai 20

Ribu Ton. Metrotvnews.com. 23 April 2010 18:30 WIB.

Brower, J. 2003. Stored Product Management. Oklahoma Cooperative Extension Service Division of Agricultural Sciences and Natural Resources Oklahoma State University. www.okstate.edu/ag/aged cm4h/. (Diakses pada tgl 9 Maret 2011).

Buntin, G. D., S. P. Keith., M.J. Weiss and James A. Webster. 2007. Handbook of Small Grain Insects. photographs, maps, and identification keys. Entomological Society of America and APS PRESS.
Ebeling, W. 2002. Pests Of Stored Food Products. Urban Entomology. Chapter 7. www.entomology.ucr.edu/ebeling/ebeling 7. (Diakses pada tgl 9 Maret 2011).

Fitria, Y., F. Farhanny., M. Bakhrir., B. Andrixinata., dan F.A.N. Sidig. 2009. Preferensi Makan dan Berkembangbiak Serangga Hama Gudang. Departemen Proteksi Tanaman, Fakultas Pertanian, IPB. (Diakses pada tgl 12 Maret 2011).

Ghimire, M. N and W.P. Thomas. 2002. Host Suitability of Various Stored Product Insects for Two Strains of the Parasitoid Anisopteromalus calandrae (Hymenoptera: Pteromalidae). Oklahoma State University, Entomology and Plant Pathology, 127 Noble Research Center, Oklahoma State University, Stillwater, OK. www.esa.confex.com/esa/2002/ techpro gram/paper_7687.htm.

Halstead, D. G. H. 1986. Key For The Identification of Beatles Associated With Stored Products. Journal of Stored Product Research, Vol 22. No.4 1986.

Harahap, L. H. 2003. Mengenal Lingkungan dan Perkembangan Hama Pascapanen. Balai Besar Karantina Pertanian Belawan. www.bbkpbelawan.deptan.go.id/Hama\%2 0 Pasca\%20panen.pdf. (Diakses pada tgl 12 Maret 2011).

Huffacker, C. B and P. S. Messenger. 1976. Theory and Practice of Biology Control. Academic Press Inc. London

Kalshoven, L.G.E. 1981. Pests of Crops in Indonesia. Revised and Translated by P.A Van der Laan. P.T. Ichtiar Baru van Hoove, Jakarta.

Kartasapoetra, A.G. 1991. Hama Hasil Tanaman Dalam Gudang. Rineka Cipta. Jakarta.

Mangoendihardjo, S. 1978. Hama - Hama Hasil Tanaman Pertanian di Indonesia Jilid III. Yayasan Pembina Fakultas Pertanian Universitas Gajah Mada. Yogyakarta. 
Mejia, D. 1991. Pest control of Storage for Maize. Organisation: Food and Agriculture Organization of the United Nations (FAO). http://www.fao.org/inpho/content/ compend/textch23_04.htm. (Diakses pada tgl 9 Maret 2011).

Melchor, D. J. 1981. The Effect of Density on the Survival and Development of Sitophilus zeamais Motsch (Coleoptera; Curculionidae) in Different Maize Varieties. In Plant Protection News, BPI. Philippines. Vol. X,No.4,4-25.

Parker, S. 2009. Life Cycle of the Maize Weevil Sitophilus zeamais. http://www. ehow. com/about.life-maize-weevil-sitophiluszeamais.html. (Diakses pada tgl 12 Maret 2011).

Ridwan, M. 2009. Pengenalan Serangga Hama Gudang. Program Sudi Agroteknologi, Jurusan Budidaya Pertanian, Fakultas Tadulako.

Saenong, M. S dan A. Hipi. 2005. Hasil-hasil eknologi Pengelolaan Hama Kumbang Bubuk Sitophilus zeamais Motch (Coleoptera; Curculionida) pada Tanaman Jagung. http://webcache. googleusercontent.com/search?q=cache: $d z 9 s n n X B d r M J$ :ntt.litbang.deptan.go.id/in d/2005/TPH/hasilhasil.docthama+gudan g+komodititjagung. (Diakses pada tgl 9 Maret 2011).
Sidik, M dan H. Halid. 1983. Sistem Penyimpanan dan Perawatan Kualitas Bahan Pangan Di Badan Logistik. Risalah Seminar Nasional Pengawetan Makanan Dengan Iradiasi, Jakarta, 6-8 Juni1983. Prosiding/ Kesehatan/Pgwetan.pdf. http://digilib. batan.go. id/eprosiding/File\%20. (Diakses pada tgl 12 Maret 2011).

Sembel, D.T., F. Kaseger, dan D.S. Kandowangko. 1992. Diktat Hama-Hama Pascapanen Hasil Pertanian. Proyek Peningkatan Perguruan Tinggi. UNSRAT. Manado.

Tandiabang, J., A. Tenrirawe dan Surtikanti. 2009. Pengelolaan Hama Pasca Panen Jagung. Balai Penelitian Tanaman Serealia. http://balitsereal.litbang.deptan. go.id/leaflet /opt.pdf. (Diakses pada tgl 12 Maret 2011).

Zimmerman M. L. 1987. Identification of Ahasverus advena (Walt) (foreign grain beetle) and Ahasverus rectus (LeConte) (Coleoptera: Cucujidae) by Micromorphology of Adult Fragments Including Genitalia. http://www.ncbi.n/m.nih.gov/pubmed/3610 962 (diakses pada tanggal 27 Mei 2011). 
